\title{
Implementing a gatekeeper system to strengthen primary care in Egypt: pilot study
}

\author{
T.R. Ward $^{7}$
}

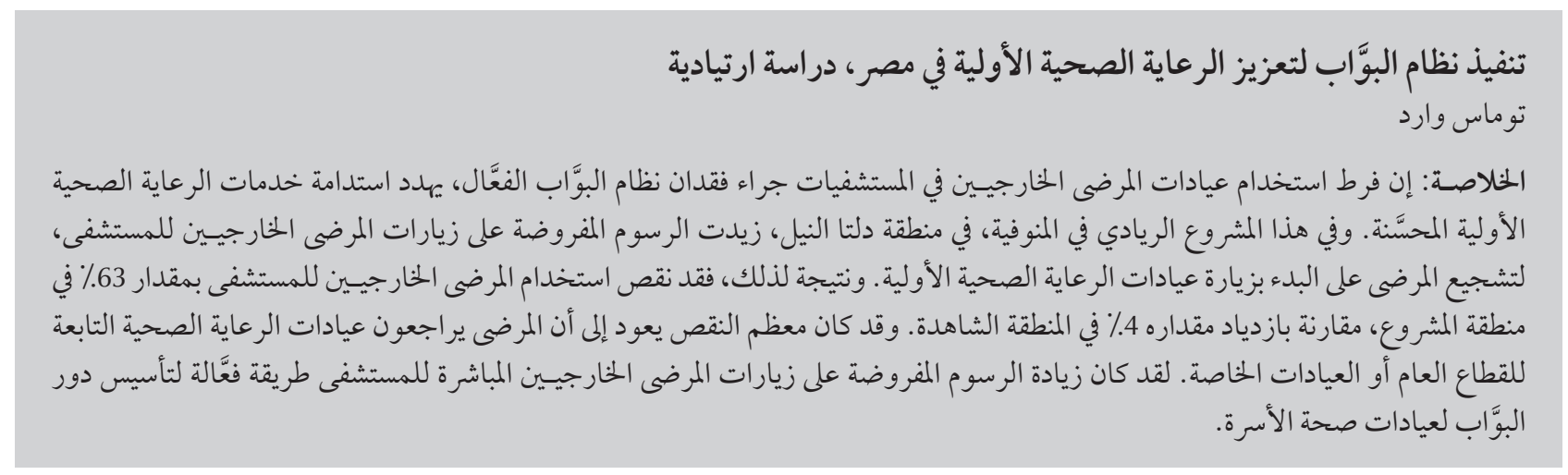

ABSTRACT Overuse of hospital outpatient clinics in Egypt, due to lack of an effective gatekeeper system, has threatened the sustainability of improved primary care services. In this pilot project in Menoufia in the Nile delta region, the price of direct hospital outpatient visits was increased, encouraging patients to attend primary care clinics first. As a result, direct hospital outpatient utilization decreased by $63 \%$ in the project area compared with a $4 \%$ increase in a control district. The majority of this reduction was accounted for by patients attending either public primary care clinics or private clinics. Increasing the price of direct hospital outpatient visits was an effective way to establish a gatekeeper role for family health clinics.

\begin{abstract}
Mise en œuvre d'un système de filtrage pour renforcer les soins de santé primaires en Égypte : étude pilote
RÉSUMÉ La surutilisation des structures hospitalières de soins externes en Égypte due à l'absence d'un système de filtrage efficace, menace la durabilité de l'amélioration des services de soins primaires. Dans ce projet pilote conduit à Ménoufia, dans la région du delta du Nil, le prix des consultations hospitalières externes directes a été augmenté, encourageant les patients à se diriger d'abord vers des établissements de soins de santé primaires. De ce fait, le recours aux soins hospitaliers externes directs a chuté de $63 \%$ dans la région concernée par le projet, alors qu'une augmentation de $4 \%$ a été constatée dans une autre région, servant de témoin. Cette diminution s'explique en grande partie par le fait que les patients se sont rendus soit dans des établissements publics de soins de santé primaires, soit dans des structures privées. L'augmentation du prix des consultations hospitalières externes directes s'est avéré un moyen efficace de mettre en place un filtrage pour les orienter vers les établissements de soins de santé de la famille.
\end{abstract}




\section{Introduction}

Egypt has improved its health outcomes over the past 4 decades, with life expectancy increasing from 44.9 years in 1960 to 68.8 years in 2005 [1]. However, with thes health profile beginning to resemble that of more affluent nations in the region [2], it is important that Egypt strengthen its primary care system to manage the increasing prevalence of chronic diseases [3]. This is a challenge not only for Egypt but for all countries in the Eastern Mediterranean Region, where the burden of chronic disease is high [4].

One way to develop primary care is to establish a gatekeeper system that eliminates direct patient access to hospitals and specialists for all but emergency treatment [5]. In the Middle East and surrounding region, few countries have implemented an effective gatekeeper role within their health systems $[6,7]$, despite evidence that gatekeepers reduce the overall cost of health care and provide other benefits. These include strengthening the position of primary care within the health system, making health care more geographically and financially accessible [8], promoting coordinated and ongoing care for complex chronic diseases such as diabetes [9], enhancing patient satisfaction and improving overall health outcomes, such as all-cause mortality [10-13].

International donors have invested heavily in reforming Egypt's primary care system over the past decade, resulting in the family health model (FHM), which currently exists in 5 of Egypt's 27 governorates, and is being rolled out across the country [14]. The FHM delivers curative and preventive care services, with a performance-based incentive scheme for staff and an accreditation programme to ensure quality is maintained. Although the FHM helps improve the quality of care [15], it costs approximately twice the amount contributed by the government. The additional cost is currently covered by international donors, a situation that is unsustainable. Early attempts to improve the sustainability of the clinics through small patient co-payments reduced utilization by $50 \%-70 \%$ [A. Dorghamy, personal communication, 2006], partly because patients started seeking primary care from hospital outpatient clinics, where a lower price was charged. As a result, hospital utilization increased dramatically.

The objective of this study was to implement and evaluate a pilot project to encourage patients to attend FHM clinics instead of seeking primary care from hospitals. The rationale for increasing utilization of FHM clinics was to improve their sustainability by boosting revenues and to enhance the effectiveness of public health programmes conducted there.

\section{Methods}

\section{Overview of health care facilities}

Various health facilities were investigated in this study. FHM clinics provided preventive and basic curative care, including immunizations, family planning, primary care consultations, minor procedures such as wound management, and investigations such as urinalysis. General public hospitals provided both inpatient and outpatient services across a range of specialties including but not limited to: cardiology, dermatology, orthopaedics and internal medicine. Specialist public hospitals provided care in a single field, such as ophthalmology. Private clinics were not investigated in this study, but were staffed by specialists and/or primary care physicians, and offered a range of services which varied from clinic to clinic. Private clinics did not provide preventive care.

\section{Changes to the system}

For the pilot project, beginning midJuly to 1 August 2006, 3 main changes were made to the system to encourage patients to attend FHM clinics.

\section{Changes to hospital pricing}

Prior to the pilot programme, patients who chose to use FHM clinics paid an annual registration fee of 10 Egyptian pounds (LE), with 3 LE for each curative primary care visit and $33 \%$ of the retail price for prescribed pharmaceuticals. Preventive care visits were free. The pricing at FHM clinics remained unchanged during the pilot study.

Before the programme, patients paid only $1 \mathrm{LE}$ for a hospital specialist visit (US\$ 0.17 ), around $0.04 \%$ of average annual per capita expenditure in Menoufia [16]. Prescribed pharmaceuticals were free. During the pilot project the cost of direct visits to hospitals were increased as follows. All non-emergency patients who attended hospitals without a referral were required to pay $10 \mathrm{LE}$ (US\$ 1.70), plus the full retail price of pharmaceuticals (Table 1). Those who attended hospital via a referral from the FHM clinic, paid a $10 \mathrm{LE}$ annual registration fee at the hospital, plus $2 \mathrm{LE}$ for each referred hospital visit and 50\% of the price of pharmaceuticals at the hospital. Patients insured with the national health insurance organization (HIO) were exempt from paying the referral fees, as the $\mathrm{HIO}$ was responsible for paying on their behalf.

\section{Changes to clinic operations}

A marketing campaign was conducted to increase awareness of the services offered at FHM clinics and to attract more patients. Marketing methods included door-to-door visits, flyers, posters and announcements in mosques. The evening opening hours were shifted so that FHM clinics closed at 22:00 hours instead of 20:00 hours. Doctors' payments were linked to the number of patients who attended their FHM clinics, creating an incentive for them to boost utilization.

Implementation of an exemption policy

A house-to-house survey was conducted to identify the poorest $10 \%$ of the population, who were given a card 


\begin{tabular}{|c|c|c|c|c|}
\hline \multirow[t]{2}{*}{ Variable } & \multicolumn{4}{|c|}{ Cost of service (LE) ${ }^{\mathrm{a}}$} \\
\hline & $\begin{array}{l}\text { Before pilot: } \\
\text { direct hospital visit }\end{array}$ & $\begin{array}{l}\text { During pilot: } \\
\text { direct hospital visit }\end{array}$ & $\begin{array}{c}\text { During pilot: } \\
\text { hospital visits via } \\
\text { primary care referral }\end{array}$ & $\begin{array}{l}\text { Before \& during pilot: } \\
\text { FHM clinic visit }\end{array}$ \\
\hline Annual registration fee & 0 & 0 & 10 & 10 \\
\hline Fee per visit & 1 & 10 & 2 & 3 \\
\hline Pharmaceuticals fee & 0 & $\begin{array}{l}\text { 100\% of retail price } \\
\text { (approx. 9-30) }\end{array}$ & $\begin{array}{l}\text { 50\% of retail price } \\
\text { (approx. 5-15) }\end{array}$ & $\begin{array}{l}\text { 33\% of retail price } \\
\text { (approx. 3-10) }\end{array}$ \\
\hline Total cost (1st visit) & 1 & $19-40$ & $17-27$ & $16-23$ \\
\hline Total cost (subsequent visits) & 1 & $19-40$ & $7-17$ & $6-13$ \\
\hline
\end{tabular}

${ }^{a}$ All prices in Egyptian pounds (LE). 1 LE =0.04\% of the average annual per capita expenditure in Menoufia [16].

which exempted them from FHM clinic fees and from hospital fees if they were referred via an FHM clinic. The criteria for exemption were based on proxies for wealth, such as employment status and material possessions, and the presence of any chronic illness within the family, such as permanent disability (e.g. quadriplegia, blindness, cerebral palsy), malignancies (e.g. haematological), genetic

illnesses (e.g. cystic fibrosis or muscular dystrophy) or chronic disabling conditions (e.g. diabetes, liver failure, kidney failure or asthma).

\section{Study design}

\section{Study area}

The pilot study was conducted in 25 FHM clinics in Menouf district of Menoufia governorate (Figure 1), which is

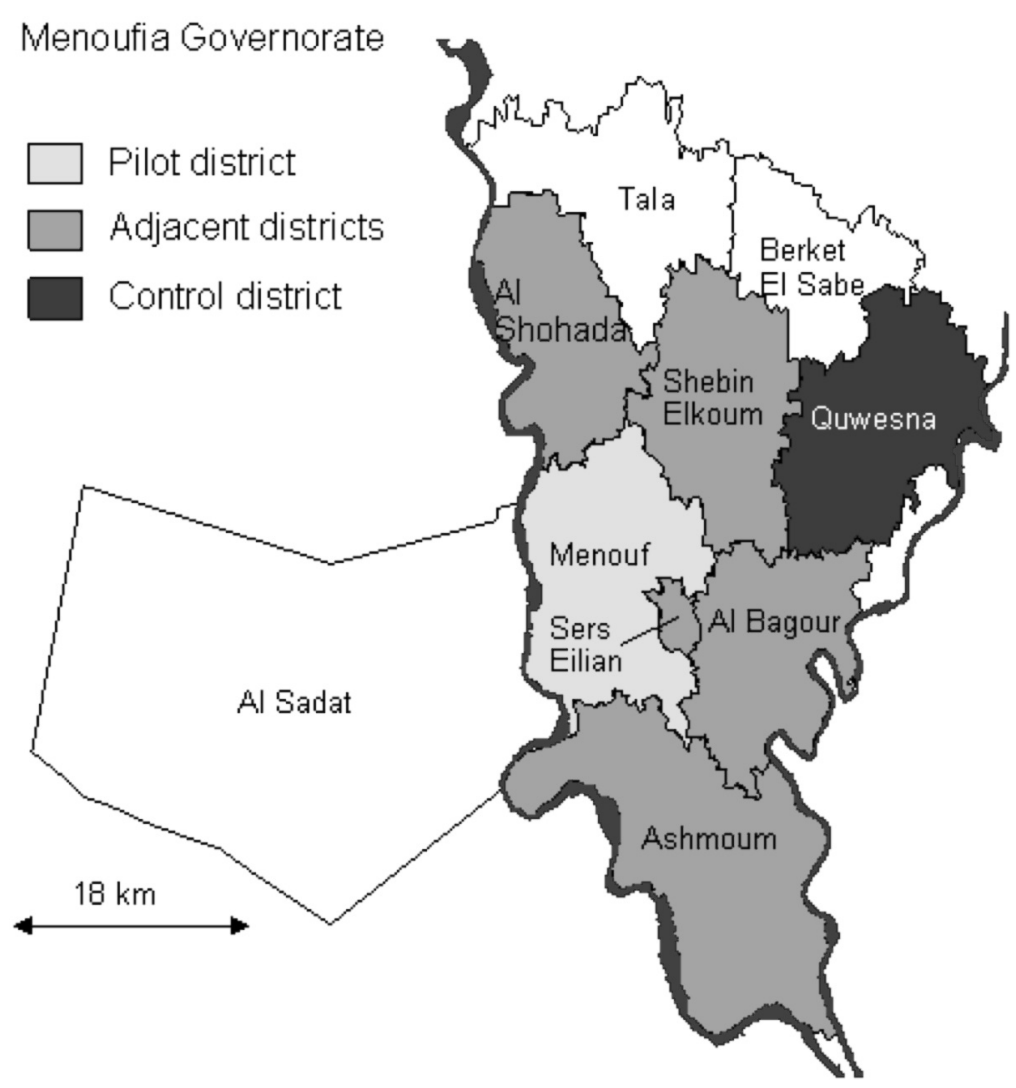

Figure 1 Map of the study area, showing Menouf (pilot project district) and Quwesna (control district)

situated between Cairo and Alexandria, in the Nile delta, and has a population of around 391000 . Menouf was chosen as the pilot district because it is in an 'average' Egyptian governorate, ranking 12th out of 27 according to the United Nations Development Programme development index [16], which accounted for factors such as life expectancy, adult literacy and real gross domestic product per capita. Menouf was also chosen because it was one of the few districts in which all clinics had implemented the FHM, and it had a reliable data collection system. The district had 4 hospitals serving its population: general, ophthalmology, fever and chest hospitals.

In 5 adjacent districts the same changes were implemented as in Menouf, so as to limit the number of patients who might travel to districts which had not implemented changes. The only adjacent district in which the changes were not implemented was Al Sadat, but it is separated from Menouf by the river Nile, making travel between the 2 districts difficult.

A control district was established in Quwesna, where there were 23 FHM clinics, 1 small general hospital and a population of 294000 . Additional hospital services for Quwesna residents were obtained from a university hospital in an adjacent district. No changes were applied in Quwesna during the pilot. It was selected as the control because it was not adjacent to Menouf, so leakage 
of patients was limited, and it had reliable data collection systems.

\section{Data collection}

The study was conducted by staff and consultants of the Egyptian Ministry of Health and Population who had extensive experience in administering pilot programmes of health system reform.

\section{Utilization data}

FHM clinics and public hospitals in Menouf and Quwesna collected daily utilization data. In FHM clinics, this was measured as the total number of patient visits each day. In limited cases where data were not available, the clinic was assigned the district average. In hospitals, daily utilization was measured as the number of visits to hospital outpatient clinics. Monthly utilization was calculated for FHM clinics and hospitals by aggregating the daily utilization data. Averageutilization in the baseline period before the changes were implemented (April-June 2006) was compared with the utilization in the 4 months following the changes (August-November 2006).

\section{Household survey}

In addition to collecting hospital and clinic utilization data, a survey of households in Menouf was conducted to determine how patients had altered their care-seeking behaviour as a result of the changes made to the system. To have adequate power, the survey required at least 384 subjects who had needed medical treatment within the previous 3 months to achieve a 5\% margin of error (a level 95\%). It was assumed that at least 1 in 3 households had a member who required medical treatment during the past 3 months. Therefore, almost 3 times the required number of households were sampled $(n=1106)$.

A social worker in each clinic was giving training and then surveyed approximately 40 households in each village. Every 10th house along the major roads of each village was surveyed. The researcher completed a structured survey form which contained 3 questions about demographics for each member of the household (name, age, address), plus 13 questions about illnesses, care-seeking behaviour and attitude towards and awareness of the changes implemented during the pilot programme. Each household was asked if a family member had required medical treatment during the previous 3 months (during the pilot project, September -November 2006), how many times they were sick, where they sought care and where they would have sought care before the changes to the system. Respondents who had chosen not to use a public hospital after the pilot project commenced were asked to give reasons.

\section{Statistical analysis}

Data were analysed in Microsoft Excel. Complete utilization datasets for FHM clinics and public hospitals were obtained for both Menouf and Quwesna, eliminating the need for sampling and further statistical analysis.

\section{Results}

\section{Utilization data}

The period during which hospital fees were increased corresponded to a decrease in outpatient visits in Menouf by between 44\% (at the general hospital) and $86 \%$ (at the chest hospital) relative to the average of the baseline period (April-June). The overall reduction in visits to the 4 Menouf hospitals was $63 \%$ in August relative to the baseline period and decreased further in September and October, compared with a slightly increased utilization in the Quwesna general hospital of $4 \%$ (Table 2).

In contrast, utilization at FHM clinics in Menouf increased by $25 \%$ in August relative to the baseline, and was still $18 \%$ above the baseline in November (Table 3). Patients who were exempted from paying fees (10\% of the population) accounted for $12 \%$ of FHM clinic visits. In Quwesna, utilization at FHM clinics decreased relative to the baseline, reaching 23\% below baseline in November.

Despite the increase in utilization at FHM clinics in the control district between the baseline and August (approximately 6150 visits), this did not account for the total reduction in hospital visits (approximately 16800 visits). The household survey therefore investigated

Table 2 Hospital outpatient clinic visits to Menouf and Quwesna hospitals in 2006 before (baseline, April-June) and during the pilot project (August-November)

\begin{tabular}{|c|c|c|c|c|c|}
\hline \multirow[t]{2}{*}{ District } & \multicolumn{5}{|c|}{ Total clinic visits } \\
\hline & Baseline & August & September & October & November \\
\hline \multicolumn{6}{|l|}{ Menouf $f^{a}$} \\
\hline No. & 26846 & 10031 & 8652 & 8882 & 10156 \\
\hline Compared to baseline (\%) & - & -63 & -68 & -67 & -62 \\
\hline \multicolumn{6}{|l|}{ Quwesnab } \\
\hline No. & 3074 & 4258 & 4037 & 3192 & 4383 \\
\hline Compared to baseline (\%) & - & +39 & +31 & +4 & +43 \\
\hline
\end{tabular}

${ }^{a}$ Pilot district; ${ }^{b}$ control district. 


\begin{tabular}{|c|c|c|c|c|c|}
\hline \multirow[t]{2}{*}{ District } & \multicolumn{5}{|c|}{ Total clinic visits } \\
\hline & Baseline & August & September & October & November \\
\hline \multicolumn{6}{|l|}{ Menouf ${ }^{a}$} \\
\hline No. & 24933 & 31076 & 24411 & 25535 & 29480 \\
\hline Compared to baseline (\%) & - & +25 & -2 & +2 & +18 \\
\hline \multicolumn{6}{|l|}{ Quwesna $^{b}$} \\
\hline No. & 27419 & 21111 & 17949 & 17769 & 21085 \\
\hline Compared to baseline (\%) & - & -23 & -35 & -35 & -23 \\
\hline
\end{tabular}

${ }^{a}$ Pilot district; ${ }^{b}$ control district.

changes in care-seeking behaviour of a sample of patients during the project.

\section{Household survey}

Of 1106 households surveyed, a total of 680 households reported that at least 1 person in the house had required medical treatment during the previous 3 months. Of these patients 437 reported that they would have sought treatment at the hospital prior to the pilot programme. After the intervention was implemented (SeptemberNovember), only 155 (35.5\%) of these patients had chosen to use a hospital [95\% confidence interval (CI) 31.0\%$39.9 \%$ ], $25.4 \%$ of patients (95\% CI: 21.3\%-29.5\%) had attended an FHM clinic instead of a hospital, $23.1 \%$ (95\% CI: $19.2 \%-27.1 \%$ ) had chosen a private clinic, while $3.9 \%$ (95\% CI: $2.1 \%-5.7 \%$ ) had not sought care from any of the different providers listed and possibly had not received any care (Table 4). Of the 282 patients who had not visited a hospital as they normally would, $62.0 \%$ (95\% CI: 57.5\%-66.6\%) cited the price increase at hospitals as the main reason for their change in behaviour, while a further 19.0\% (95\% CI: 15.3\%-22.7\%) cited quality issues. Other reasons (less than $5 \%$ each) included: distance to the hospital too far; preferred to go to a private physician; and having to wait too long at the hospital.

\section{Discussion}

Primary care reform programmes in developing countries generally focus on improving quality, but at a higher cost, which raises the issue of sustainability. At first, the higher cost is absorbed by

\begin{tabular}{lcc}
\hline $\begin{array}{l}\text { Table } 4 \text { Types of health care providers used during the pilot project by patients } \\
\text { who would have attended public hospital before direct hospital fees were } \\
\text { increased in Menouf }\end{array}$ & No. of patients \\
\hline Health care provider & 155 & 35.5 \\
Public hospital & 111 & 25.4 \\
FHM clinic & 101 & 23.1 \\
Private clinic & 18 & 4.1 \\
Private pharmacy & 13 & 3.0 \\
Private clinic (referred from FHM clinic) & 11 & 2.5 \\
NGO clinic & 6 & 1.4 \\
HIO hospital & 5 & 1.1 \\
Private hospital & 17 & 3.9 \\
Other & 437 & 100.0 \\
Total &
\end{tabular}

FHM = family health model; $N G O=$ nongovernmental organization; $H I O=$ health insurance organization .

donor funds, but these are generally finite, and must eventually be covered either through patient or government contributions. When patients are asked to pay more for treatment, they are likely to alter their behaviour if cheaper options are available. Therefore, it is important to coordinate the pricing of primary care clinics and hospitals to ensure primary care physicians act as gatekeepers.

During this pilot project when hospital fees were increased, there was a substantial $63 \%$ reduction in visits to the 4 Menouf hospitals relative to the baseline period, compared with a $4 \%$ increased utilization in the control general hospital in Quwesna. The slight increase in utilization in Quwesna may indicate a spillover effect from Menouf to Quwesna, as despite the distance, a few patients may have travelled to the Quwesna hospital to avoid paying higher hospital fees in Menouf and surrounding districts. There was a corresponding increase in utilization of the FHM clinics in Menouf and a decrease in Quwesna during the pilot project. Part of the decrease in utilization at FHM clinics in Quwesna may have been due to reductions in utilization around the holy month of Ramadan, which occurred during October. Considering the large reduction in the control district, the more modest increases in the pilot district may disguise a more significant upward trend.

Before this pilot study, utilization of hospital outpatient clinics in Menouf 
(0.85 visits per capita per year) was higher than in a selection of other countries including England (0.76), Spain (0.55), France (0.44) and the United States (0.29) [17-19]. However, up to $60 \%$ of Egypt's population is reported to use private clinics [20], suggesting that overuse was even greater within the subset of the population using public hospitals. During this pilot study, annual hospital outpatient visits per capita reduced to approximately 0.29 in Menouf, which was lower than in European countries and about the same as in the United States.

Considering that access to hospital outpatient facilities was almost free before the pilot study, it is not surprising that FHM clinics were not fulfilling a gatekeeper role, with an average of 1.24 hospital visits for each visit to the FHM clinic. In England, where a gatekeeper system is well established, widely accepted and enforced, a mere 0.17 visits are made to the hospital per visit to the GP [17]. After the pilot study in Menouf, approximately 0.34 hospital visits were made for each visit to the FHM clinic. Hence, despite not emulating the UK's gatekeeper system, the pilot system in Menouf was successful in directing patients away from hospitals towards primary care.

No other studies were found in the literature that quantify the effect of a newly implemented gatekeeper system on the utilization of primary and secondary care. Hence the current study will provide comparative data for future studies.

It should be noted that the observation period of 4 months was quite short, so caution should be applied before extrapolating these results, especially since other experiments with gatekeeper systems did not reveal their full effects within the first year [21].

\section{Conclusions}

Increasing the price of direct hospital outpatient visits was an effective way to establish a gatekeeper role for FHM clinics and discourage overuse of hospital outpatient clinics. Patients who altered their care-seeking behaviour predominantly chose FHM and private clinics instead of hospitals. The increase in FHM clinic utilization, and likely increase in revenues, may improve their sustainability.

\section{References}

1. Saleh WF. Reforming Egypt's health system: is it that simple? British medical journal, 2006, 333:859-60.

2. World health report: reducing risk, promoting healthy life. Geneva, World Health Organization, 2002.

3. Nishtar S. Lessons in tackling chronic disease. British medical journal, 2006, 333:820.

4. Preventing chronic disease-a vital investment. Geneva, World Health Organization, 2005.

5. Willems DL. Balancing rationalities: gatekeeping in health care. Journal of medical ethics, 2001, 27(1):25-9.

6. Siegel-Itzkovich J. Israel moves to GP gatekeeper system. British medical journal, 1998, 317:432.

7. Tabenkin $\mathrm{H}$ et al. Patients' views of direct access to specialists: an Israeli experience. Journal of the American Medical Association, 1998, 279(24):1943-8.

8. Ferrer RL, Hambidge SJ, Maly RC. The essential role of generalists in health care systems. Annals of internal medicine, 2005, 142(8):691-9.

9. Al-Khaldi YM, Khan MY. Impact of a mini-clinic on diabetic care at a primary health care center in southern Saudi Arabia. Saudi medical journal, 2002, 23(1):51-5.

10. Macinko J, Starfield B, Shi L. The contribution of primary care systems to health outcomes within Organization for Economic Cooperation and Development (OECD) countries, 1970-1998. Health services research, 2003, 38(3):831-65.

11. Martin DP et al. Effect of a gatekeeper plan on health services use and charges: a randomized trial. American journal of public health, 1989, 79(12):1628-32.
12. Etter JF, Perneger TV. Health care expenditures after introduction of a gatekeeper and a global budget in a Swiss health insurance plan. Journal of epidemiology and community health, 1998, 52(6):370-6.

13. Starfield B. Is primary care essential? Lancet, 1994, 344:1129-33.

14. Boker J et al. An international physician education program to support the recent introduction of family medicine in Egypt. Family medicine, 2004, 36(10):739-46.

15. Zaki B et al. Patient satisfaction with primary health care services in two districts in lower and upper Egypt. Eastern Mediterranean health journal, 2003, 9(3):422-9.

16. Egypt human development report. New York, United Nations Development Programme, 2005.

17. Outpatient data 2005. Hospital episode statistics [website] (http://www.hesonline.nhs.uk, accessed 15 January 2010).

18. Encuesta de morbilidad hospitalaria 2004 [Hospital morbidity survey 2004]. Madrid, Spain, Spanish National Statistical Institute, 2004.

19. Middleton K, Hing E. National Hospital Ambulatory Medical Care Survey: 2002 outpatient department summary. Advance data from vital and health statistics, 2004, 345.

20. El-Henawy A. Current situation, progress and prospects of health for all in Egypt. Eastern Mediterranean health journal, 2000, 6(4):816-21.Coulter A, Bradlow J. Effect of NHS reforms on general practitioners' referral patterns. British medical journal, 1993, 306:433-7. 